\title{
Spectra Measurements Using Piezoelectric Diaphragms to Detect Burn in Grinding Process
}

\author{
Danilo M. S. Ribeiro, Paulo R. Aguiar, Luiz F. G. Fabiano, Doriana M. D’Addona, \\ Fabricio Guimarães Baptista, Member, IEEE, and Eduardo C. Bianchi
}

\begin{abstract}
Researchers have evaluated a great number of monitoring techniques in order to control the surface condition of ground parts. Piezoelectric diaphragms of lead zirconate titanate are used in many fields, but these sensors are not common in the monitoring of the machining processes. This paper proposes a method for monitoring the workpiece surface condition (normal grinding and burn) by using a piezoelectric diaphragm and feature extraction techniques. A comparison is made with a conventional acoustic emission sensor, which is a traditional sensor in the monitoring of the machining processes. Grinding tests were performed in a surface-grinding machine with Society of Automotive Engineers (SAE) 1045 steel and cubic boron nitride (CBN) grinding wheel, where the signals were collected at $2 \mathrm{MHz}$. The workpieces were thoroughly analyzed through visual inspection, surface roughness and hardness measurements, and metallographic analyses. Study on the frequency content of both signals was carried out in order to select bands closely related to the workpiece surface condition. Digital filters were applied to the raw signals and features were extracted and analyzed. The root mean square values filtered in the selected bands for both sensors presented a better fitting to the linear regression, which is highly desirable for setting a threshold to detect burn and implementing into a monitoring system. Also, the basic damage index results show an excellent behavior for grinding burn monitoring for both sensors. The method was verified by using a different grinding wheel, which clearly shows its effectiveness and demonstrates the potential use of the low-cost piezoelectric diaphragm for grinding burn monitoring.
\end{abstract}

Index Terms-Acoustic emission (AE), condition monitoring, manufacturing processes, piezoelectric transducer.

\section{INTRODUCTION}

G RINDING is one of the most complicated process, largely, due to the fact that a grinding operation

Manuscript received March 15, 2017; revised May 15, 2017; accepted July 04, 2017. Date of publication August 11, 2017; date of current version October 9, 2017. This work was supported in part by the National Council for Scientific and Technological Development, CNPq, Brazil, under Grant 306677/2013-0, and in part by Coordination for the Improvement of Higher Education Personnel, CAPES, Brazil. The Associate Editor coordinating the review process was Dr. Mohamed Abou-Khousa. (Corresponding author: Paulo R. Aguiar.)

D. M. S. Ribeiro, P. R. Aguiar, and F. G. Baptista are with the São Paulo State University (UNESP), School of Engineering, Bauru, Department of Electrical Engineering, Bauru 17033-360, Brazil (e-mail: danilomarcus@outlook.com; aguiarpr@feb.unesp.br; fabriciogb@feb.unesp.br).

L. F. G. Fabiano and E. C. Bianchi are with the São Paulo State University (UNESP), School of Engineering, Bauru, Department of Mechanical Engineering, Bauru 17033-360, Brazil (e-mail: luiz_gilli@hotmail.com; bianchi@feb.unesp.br).

D. M. D'Addona is with the Department of Chemical, Materials and Industrial Production Engineering, University of Naples Federico II, 80125 Naples, Italy (e-mail: daddona@unina.it).

Color versions of one or more of the figures in this paper are available online at http://ieeexplore.ieee.org.

Digital Object Identifier 10.1109/TIM.2017.2731038 is performed by a grinding wheel which is composed of many tiny, irregular shaped, and randomly positioned and oriented abrasives (also called grits) bonded by some medium. Thus, there are many variables that make it difficult to choose the optimal parameters in a simple way [1].

Since a reduction of the production costs and an improvement in the quality of the machined parts is expected, the automated detection of the machining process malfunctions has become of great interest among scientists and industrialists. By the use of a large variety of sensors, monitoring of the machining processes represents the prime step for reduction of poor quality and hence cost reduction [2].

According to [3], in light of its superior sensitivity to the multitude of fine dynamic interactions between the wheel and the workpiece, conventional acoustic emission (AE) has emerged as a valuable tool in a host of monitoring applications in grinding. It has been demonstrated by several research works, such as in [4]-[10], that AE technique is an important tool for the machining process monitoring, and the root mean square (RMS) of the AE signal has correlation with force, workpiece burn, tool condition, and surface roughness.

The use of low-cost piezoelectric diaphragms has been reported in many research on several applications [11]-[14]. These transducers are generally employed in audio signaling devices due to the simple structure consisting of a piezoelectric ceramic disc adhered to a brass plate. They are available from many manufacturers, such as Murata Manufacturing (Nagaokakyo-shi, Kyoto, Japan), and are easily purchased at a low cost, ranging from cents to a few dollars, depending on the size and manufacturer [11].

One of the most critical problems in the grinding process is the automatic detection of surface burn in the parts. The burn occurs during the cutting of the part by the grinding wheel when the amount of energy generated in the contact area produces an increase of temperature enough to produce a change of phase in the material. In general, such occurrence can visually be observed by the bluish temper color on the part surface, but more generally time-consuming tests are required for its after-the-fact determination [6], [15]. The hardness measurements and chemical inspection by etching the surface in Nital etchant are the most common tests for quality control regarding burn occurrence in grinding. Other tests can also be used such as the magnetic Barkhausen noise method and eddy-current method [16]. 
According to [17], surface finish significantly influences the functioning of machine parts. It also affects the resistance to wear, load carrying capacity, tool life, resistance to corrosion, fatigue resistance and ability to hold pressure, and noise reduction in case of gears. The author still state that the most important parameter describing surface integrity is surface roughness. In the manufacturing industry, surfaces must be within certain limits of roughness. Therefore, measuring surface roughness is vital to quality control of the machined workpiece.

On the other hand, indirect methods of monitoring or inspection of surface integrity of parts that depend on signals from sensors such as forces, power, vibration, and AE are more desirable mainly because they are nondestructive, nonintrusive, and the interruption of the process is not required. Thus, the development of reliable and robust monitoring system to assess the workpiece surface condition in grinding is of great importance for an unattended and automated machining process.

This paper proposes a method for monitoring the workpiece surface condition (normal grinding and burn) by using a passive piezoelectric diaphragm of PZT (lead zirconate titanate) and feature extraction techniques. A comparison is made with conventional AE sensor, which is a very traditional sensor in the monitoring of the machining processes.

What makes this research work distinguishable is the use of a PZT diaphragm to monitor the workpiece surface conditions, which is a low-cost sensor compared to conventional AE sensors. Besides, study on the frequency domain of the PZT signal that closely relates frequency bands to normal and grinding burn has not yet been carried out as presented. The use of the RMS deviation (RMSD) and correlation coefficient deviation metric (CCDM) indices is new as applied to passive sensors in this research. Finally, the assessment of the workpiece condition is performed by experimental tests using two important industrial grinding wheels and workpieces of society of automotive engineers (SAE) 1045 steel in order to assure the efficiency of the proposed method.

It is worth mentioning that there are important practical merits behind the various monitoring system parameters of this paper. The grinding burn occurrence impairs the highvalue-added part being machined and thus leads to significant financial losses, since the grinding process is in general the last stage of the manufacturing chain. On the other hand, the control of surface roughness through the proposed monitoring system is of great importance in the manufacturing industries, as it plays a key role in the quality of the precision part. In regard to the material and grinding wheel used in this paper, they are largely employed in the manufacturing of a great variety of components for the automotive and aeronautic industries, for instance. Finally, the selection of frequency bands of AE and PZT signals provided better results when compared to the whole spectrum signals and, therefore, a more efficient and reliable monitoring system is obtained.

\section{Grinding Process Monitoring}

Grinding process monitoring has been the focus of many investigations, since it is of major importance toward the process optimization and in turn lowering production costs.
One of the main grinding parameters used to study the process mechanics and in turn the process monitoring is the equivalent chip thickness (heq), which is a measure of the grinding condition and proportional to the depth of cut and workpiece speed, and inversely proportional to the peripheral grinding wheel speed [18].

On the other hand, it is usual to monitor the grinding process by indirect methods, which rely on sensors such as AE, force, power, and vibration [19]. Vibration sensor has been used in several research works in the monitoring of the machining processes, including grinding, such as in [7], [20], and [21]. Although the frequency range of vibration signals is below the AE, these signals may be related to the process phenomenon under investigation, such as grinding burn, and therefore vibration signals based on the method or tools herein proposed can be further investigated. However, AE and power/current sensors are the most common sensors employed in grinding, as they are noninvasive and low cost in addition to their effectiveness on several monitoring applications, such as in [9], [10], and [22]-[24] to cite a few. Recently, a lowcost PZT diaphragm has been tested in grinding with the use of the electromechanical impedance (EMI) method, and shed light on a new way of monitoring the process [25]. Based on the piezoelectric transducer used in [25] and other works cited previously allied to signal processing techniques, this paper proposes to assess the surface condition (normal grinding and burn) of the workpieces in the grinding process.

Many statistics and tools for monitoring the grinding process have been used such as the RMS, constant false alarm rate, mean-value deviance, kurtosis, skewness, neural network models, fuzzy models, among others [4], [10], [19], [26]-[28]. Furthermore, damage characterization indices are widely used in structural health monitoring (SHM) along with the EMI technique. The most common indices are the RMSD and CCDM, which were used with the EMI technique in grinding burn in [25].

According to [29], the RMSD index is based on a Euclidean norm and several variations of this index can be found in the literature. In this paper, the RMSD index was computed by

$$
\operatorname{RMSD}=\sum_{k=\omega_{I}}^{\omega_{F}} \sqrt{\frac{\left[X_{D}(k)-X_{H}(k)\right]^{2}}{X_{H}^{2}(k)}}
$$

where the subscripts $H$ and $D$ indicate the intact and damaged conditions, respectively, while $X_{H}(k)$ and $X_{D}(k)$ are the signatures in the frequency spectra of the structure under intact and damage conditions, respectively, and are determined at a frequency $k$ that ranges from $\omega_{\mathrm{I}}$ (initial frequency) to $\omega_{\mathrm{F}}$ (final frequency).

The CCDM index is based on the correlation coefficient and it was computed in this paper as follows [25], [29]:

$$
\mathrm{CCDM}=1-\frac{\sum_{\omega_{\mathbf{I}}}^{\omega_{\mathbf{F}}}\left[\mathbf{X}_{\mathbf{H}}(\mathbf{k})-\bar{X}_{\mathbf{H}}\right]\left[\mathbf{X}_{\mathbf{D}}(\mathbf{k})-\bar{X}_{\mathbf{D}}\right]}{\sqrt{\sum_{\omega_{\mathbf{I}}}^{\omega_{\mathbf{F}}}\left[\mathbf{X}_{\mathbf{H}}(\mathbf{k})-\bar{X}_{\mathbf{H}}\right]^{2}} \sqrt{\sum_{\omega_{\mathbf{I}}}^{\omega_{\mathbf{F}}}\left[\mathbf{X}_{\mathbf{D}}(\mathbf{k})-\bar{X}_{\mathbf{D}}\right]^{2}}}
$$


TABLE I

GRINDING TESTS CONDITIONS FOR SAE 1045 STEEL

\begin{tabular}{ccc}
\hline \hline Test & Depth of Cut $(\mu \mathrm{m})$ & heq $(\mu \mathrm{m})$ \\
\hline 1 & $5 \mu \mathrm{m}$ & 0.0193 \\
2 & $10 \mu \mathrm{m}$ & 0.0385 \\
3 & $20 \mu \mathrm{m}$ & 0.0770 \\
4 & $40 \mu \mathrm{m}$ & 0.1540 \\
5 & $80 \mu \mathrm{m}$ & 0.3081 \\
6 & $120 \mu \mathrm{m}$ & 0.4621 \\
7 & $140 \mu \mathrm{m}$ & 0.5391 \\
\hline \hline
\end{tabular}

where $X_{H}(k)$ and $X_{D}(k)$ are the signatures as defined before, and $\bar{X}_{H}$ and $\bar{X}_{D}$ are the average signatures under intact and damaged conditions, respectively, in the same frequency range.

\section{Methodology}

In this Section the following procedures will be described: experimental setup and grinding tests, visual inspections of the workpieces, surface roughness and Vickers hardness measurements, metallographic analysis, frequency bands selection and signal processing, and method verification.

\section{A. Experimental Setup and Grinding Tests}

The experimental tests were carried out in a surface-grinding machine. Each test consisted of a single grinding pass across the workpiece length. Preceding the test 1, a multipoint diamond dresser performed the dressing of the grinding wheel. Table I shows the grinding condition of each test.

An AE sensor and a processing signal unit, from Sensis manufacturer, model DM-42, were employed in the tests. In addition, a low-cost piezoelectric diaphragm (PZT), Murata Manufacturing, model 7BB-35-3, was used, which consists of a disc-shaped PZT ceramic (active element) with a diameter of $25 \mathrm{~mm}$ and thickness of $0.23 \mathrm{~mm}$ adhered concentrically on a brass disc with diameter of $35 \mathrm{~mm}$ and thickness of $0.30 \mathrm{~mm}$.

The AE sensor was fixed to the workpiece holder and the PZT transducer was bonded to it using a thin layer of cyanoacrylate glue. Additionally, the PZT transducer was covered with silicone glue to avoid the influence of external particles and humidity. Both sensors were tested for good signal sensitivity and saturation. Fig. 1 illustrates the experimental test setup. It is worth mentioning that the PZT sensor attached to the workpiece and the vibration sensor attached to the holder were not considered in this paper.

An oscilloscope, model DL850, from Yokogawa, collected both raw signals, at a sampling rate of $2 \mathrm{MHz}$. Workpieces of SAE 1045 steel (wt.\%: C: 0.43-0.50, Si: 0.17, Mn: 0.52, $\mathrm{S}:$ 0.031, P: 0.032, and $\mathrm{Fe}$ balance) along with a cubic boron nitride $(\mathrm{CBN})$ grinding wheel, model Resin 2684 01-0262 B151, were employed. The tests were performed with cutting fluid (Emulsion water-oil of $4 \%$ ), with pressure of $0.4 \mathrm{MPa}$ and flow rate of $84 \mathrm{l} / \mathrm{min}$. The temperature measured near the sensors was nearly constant and equal to $24{ }^{\circ} \mathrm{C}$.

The following grinding parameters were used in the seven experimental tests:

1) peripheral speed of the grinding wheel: $32.2 \mathrm{~m} / \mathrm{s}$;

2) workpiece speed: $0.124 \mathrm{~m} / \mathrm{s}$;

3) grinding wheel diameter: $344 \mathrm{~mm}$;

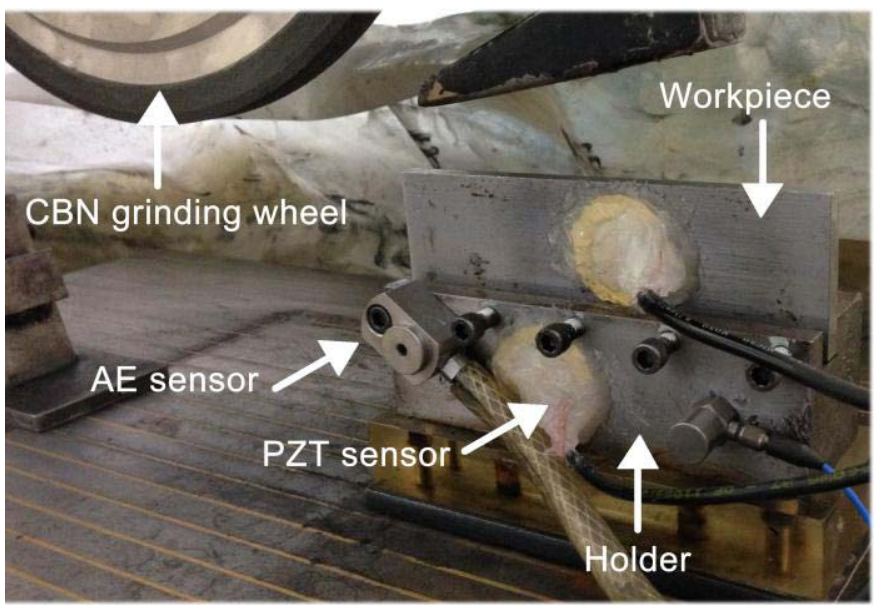

Fig. 1. Experimental test setup.

4) wheel width: $10 \mathrm{~mm}$;

5) workpiece dimensions: length $=150 \mathrm{~mm}$, width $=7 \mathrm{~mm}$.

Each grinding test consisted of a single grinding pass through the workpiece surface at a given grinding condition, as shown in Table I.

\section{B. Workpiece Surface Assessment}

Following the experiments, the average surface roughness (Ra) for each workpiece was measured, using a Taylor Hobson Surtronic 3+ precision instrument. A sampling length of $1.6 \mathrm{~mm}$ and cut-off of $0.8 \mathrm{~mm}$ was used, in accordance with the recommendations of the ISO 4288-1996 standard.

Each workpiece surface length was equally divided into 30 parts and three surface roughness measurements were taken from each part. Thus, the mean value and standard deviation of the three surface roughness measurements of each part were calculated, allowing the assessment of the ground workpiece regarding this important parameter.

Visual inspection of each workpiece surface was carefully carried out as well as workpiece surfaces were digitally photographed for further analysis.

In order to allow an in-depth analysis of the workpiece structural changes, metallographic and Vickers hardness tests were performed. For the first test, samples were properly sectioned to the area of interest by abrasive cutting. Each specimen was then mounted by encapsulating it into a compression-mounting compound (Bakelite). Polishing was subsequently performed to planarize the specimen and to reduce the damage created by sectioning. The planar polishing step was accomplished by decreasing the abrasive grit size sequentially. Finally, chemical etching with Nital 2\% was carried out for the metallographic analysis in order to optically enhance microstructural features. In the analysis and image acquisition of the samples, an Olympus microscope was used.

As regards to the Vickers hardness measurements, a Mitutoyo HM211 hardness tester was employed. Indentations were performed on each workpiece surface with a load of $500 \mathrm{~g}$, 
consisting of 11 equally spaced hardness measurements taken along the workpiece length with three repetitions. The hardness measurements were based on the ASTM E92 standard.

\section{Selection of Frequency Bands and Signal Processing}

The data sets from the tests were digitally processed in MATLAB. A study on the raw signals spectra was performed in order to identify frequency bands more strongly related to the surface condition of the workpieces. Thus, three workpieces were selected in order to represent distinct grinding condition, that is, slight, medium, and severe.

The spectrum of each signal was obtained for each surface condition by using 8192 -block fast Fourier transform and Hanning window at three equidistant points along the grinding pass. The mean of the three spectra was considered for analysis.

The selection of the suitable frequency bands for monitoring the workpiece quality is a critical process, which depends on the type of the workpiece material and dimensions, type of grinding wheel and sensor used in the data acquisition. The optimum bands are not necessarily around the highest peaks of the spectra, but those which provide greater magnitude differences related to the workpiece conditions. Therefore, the criterion used in the frequency band selection was based on searching for frequency windows in which significant magnitudes differences of the signal for each surface condition were observed. In addition, a minimum of overlap among the three condition spectra was sought. Butterworth digital filters, order 6 , for each frequency band previously selected, were applied to the raw signals, and therefore new filtered vectors were generated.

The RMS values were obtained using a block length of 2048 from the filtered vectors for each workpiece, which correspond to about $1 \mathrm{~ms}$ as recommended in [30]. The mean value and standard deviation for each test were obtained, considering only the grinding pass interval.

RSMD and CCMD indices were obtained from the spectra of each signal in the frequency band selected, using the first workpiece as the baseline, as it has undergone the slightest cutting condition without any damage. This was very encouraging because these indices reflect correlation with healthy and damaged structures when the EMI technique is applied, as can be verified, for instance, in [25] and [29]. It is worth mentioning that the indices were computed in this paper similarly as it is done in SHM applications based on the EMI technique, where these indices are widely employed. The computation is usually done in narrow frequency bands more sensitive to the structural damage or workpiece condition, which is the case of this paper. The average computation of the chosen bands could minimize the variations of the indices with regard to the workpiece condition, which is not desirable.

\section{Experimental Method Verification}

In order to verify the method proposed in this paper, grinding tests were also performed for SAE 1045, but an aluminum oxide grinding wheel was used, model 38A150 LVH
TABLE II

GRINDING TESTS CONDITIONS FOR METHOD VERIFICATION

\begin{tabular}{ccc}
\hline \hline Test & Depth of Cut $(\mu \mathrm{m})$ & heq $(\mu \mathrm{m})$ \\
\hline 1 & $5 \mu \mathrm{m}$ & 0.0214 \\
2 & $10 \mu \mathrm{m}$ & 0.0428 \\
3 & $15 \mu \mathrm{m}$ & 0.0641 \\
4 & $20 \mu \mathrm{m}$ & 0.0855 \\
5 & $25 \mu \mathrm{m}$ & 0.1069 \\
6 & $35 \mu \mathrm{m}$ & 0.1497 \\
7 & $45 \mu \mathrm{m}$ & 0.1924 \\
8 & $55 \mu \mathrm{m}$ & 0.2352 \\
\hline \hline
\end{tabular}

\begin{tabular}{|c|c|c|c|}
\hline Test 1. & Test 2. & Test 3. & Test 4. \\
\hline $5 \mu \mathrm{m}$ & $10 \mu \mathrm{m}$ & $20 \mu \mathrm{m}$ & $40 \mu \mathrm{m}$ \\
\hline Test 5. & Test 6. & Test 7. & \\
\hline $80 \mathrm{~m}$ & $120 \mu \mathrm{m}$ & $140 \mu \mathrm{m}$ & \\
\hline
\end{tabular}

Fig. 2. Surface condition of the ground workpiece at different depths of cut.

from NORTON company, which is a completely different material, but also widely used in the manufacturing industry. It is important to report that another set of workpieces was used for the verification tests. The peripheral speed of the wheel of $29 \mathrm{~m} / \mathrm{s}$ and workpiece speed of $0.124 \mathrm{~m} / \mathrm{s}$ were used in the tests. The grinding wheel dimensions are of $307.8-\mathrm{mm}$ diameter and 25.4-mm width; and the workpiece dimensions are of $150-\mathrm{mm}$ length and $7-\mathrm{mm}$ width. The same procedures for the grinding tests, workpiece measurements, frequency band selection, and signal processing were also carried out. Table II summarizes the tests performed.

\section{RESUltS AND DISCUSSION FOR SAE 1045 STEEL AND CBN WHEEL}

In this section, results and discussion for grinding of SAE 1045 steel with CBN grinding wheel are presented to demonstrate the proposed method.

\section{A. Visual Inspection of the Workpiece Surface}

The workpieces surfaces were photographed and digitalized after the grinding tests in order to visually evaluate the images and detect different conditions, such as burn and normal surface. Fig. 2 shows the results for visual inspection.

As can be seen in Fig. 2, the appearance of visible burn was strongly presented on the last two workpieces, tests 6 and 7 , where the grinding conditions were more severe. Tests 1 and 2 show no visible burn, whereas tests 3 to 5 , a slightly color change can be seen. However, according to [18], this cosmetic aspect is not enough to determine the occurrence of burn, which can be otherwise verified by using combined methods, such as metallography and hardness tests.

\section{B. Surface Roughness for SAE 1045 Steel Workpieces}

Fig. 3 shows the surface roughness values and their standard deviations obtained for each workpiece. Each value represents 


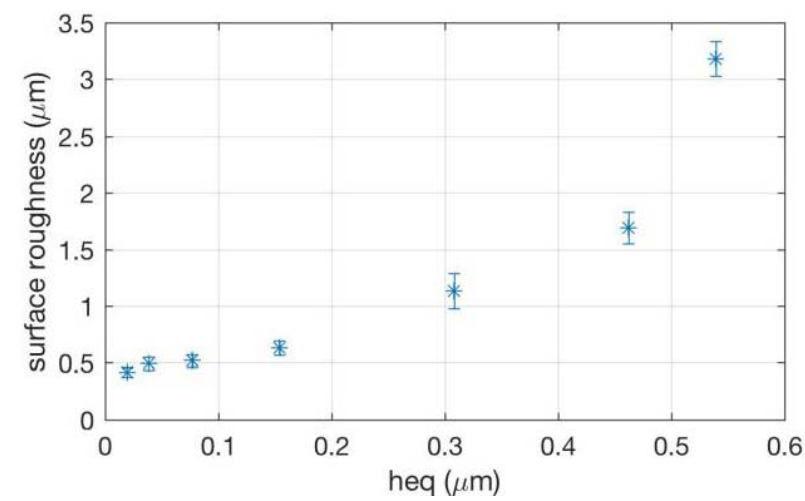

Fig. 3. Surface roughness for each workpiece.

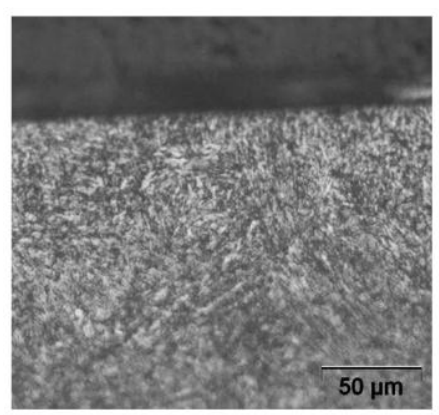

(a)

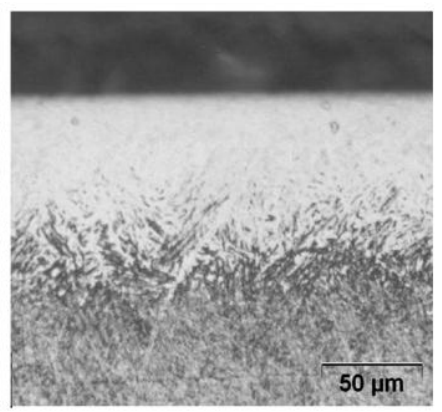

(b)
Fig. 4. Metallography for (a) good condition: workpiece 2, and (b) burn: workpiece 6 .

the mean of the roughness values transversally measured along the workpiece length.

It can be observed that the roughness values increases as the grinding condition becomes more severe and the wheel becomes worn [7]. In addition, the standard deviation values for workpieces 1-4 are small, as they belong to slight and near medium grinding condition. However, a larger standard deviation values are observed for workpieces 5-7, in which the grinding conditions ranged from medium to severe, and thus leading to higher levels of surface irregularities and workpiece burn. According to [31], the range of surface roughness obtained in the grinding process for average applications is of $0.1-1.6 \mu \mathrm{m}$. Thus, only the workpieces 6 (heq $=0.1924$ ) and 7 (heq $=0.2352)$ are out of this range.

\section{Metallography and Vickers Hardness for SAE 1045 Steel}

Fig. 4 shows examples of two distinct workpieces obtained from metallographic tests. It can be clearly seen in Fig. 4(a) that the martensitic structure of the part did not suffer changes, that is, there is no white layer formation. However, in Fig. 4(b), a white layer in the part subsurface is observed, which is caused by a significant rise in temperature, making the workpiece surface excessively harder and brittle and, therefore, proving that the burning phenomenon occurred [32], [33].

Vickers hardness measurements were also taken on the workpieces in order to better support the normal condition

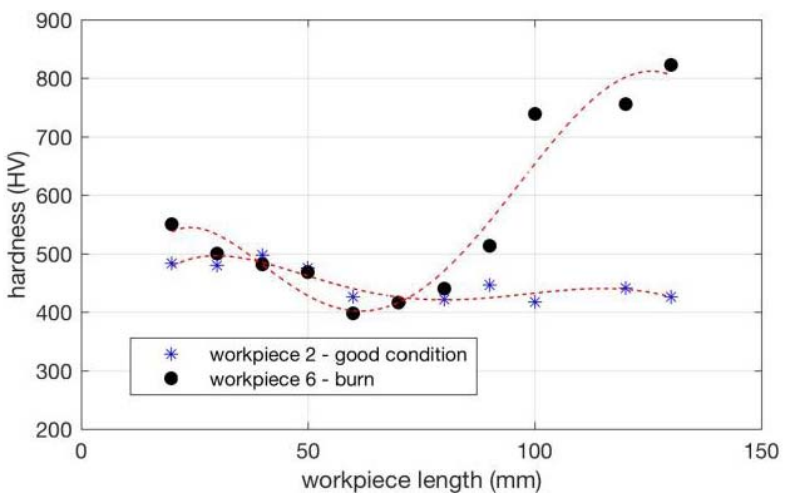

Fig. 5. Vickers hardness measurements.

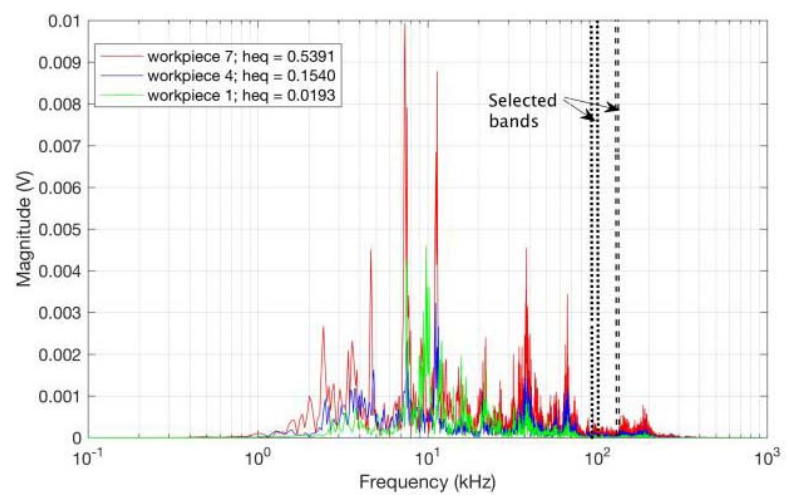

Fig. 6. Spectra of AE.

and the occurrence of burn. As we have a limited space, these measurements are shown in Fig. 5 only for workpieces 2 and 6.

It can be observed in Fig. 5 that there is no significant change in Vickers hardness values for workpiece 2, since for this tempered steel the hardness value of around $600 \mathrm{HV}$ is well acceptable. The hardness of the workpiece surface tends to decrease following the grinding process, which produces a high temperature in the contact zone between the part and the tool. On the other hand, when the workpiece surface is damaged with burn, the formation of white layer strongly increases the hardness, achieving values greater than $800 \mathrm{HV}$, as can be conferred in Fig. 5 [33].

Therefore, according to the metallographic analysis and hardness measurements, only the workpieces 6 and 7 presented burn.

\section{Selection of Frequency Bands}

Figs. 6 and 7 show the spectra of the AE and piezoelectric sensors, respectively, for three distinct grinding conditions. It can be seen that the $\mathrm{AE}$ signal has a frequency range of $1-300 \mathrm{kHz}$ and the PZT signal of $0.2-200 \mathrm{kHz}$. On the other hand, the magnitudes of the $\mathrm{AE}$ are higher than those for the PZT, which can be explained by the use of an amplifier module for the AE signal and without amplification for the PZT signal.

It can be observed in these curves that the signal magnitudes show different features in the frequency domain according to the workpiece surface condition. There exist greater signal 


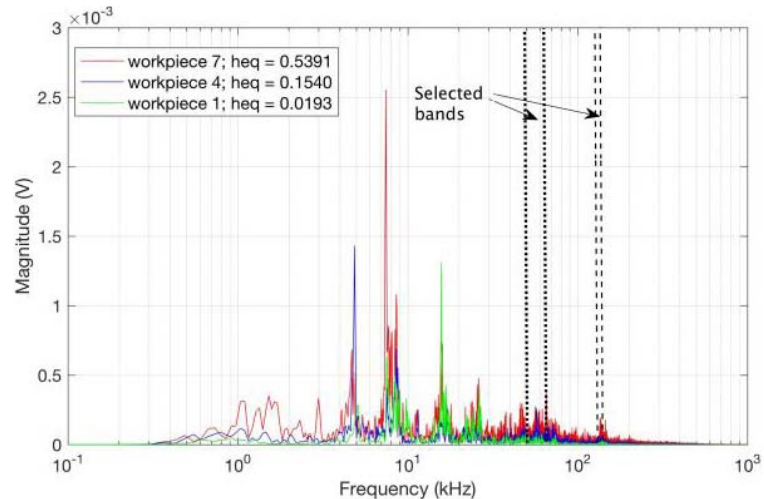

Fig. 7. Spectra of PZT signal.

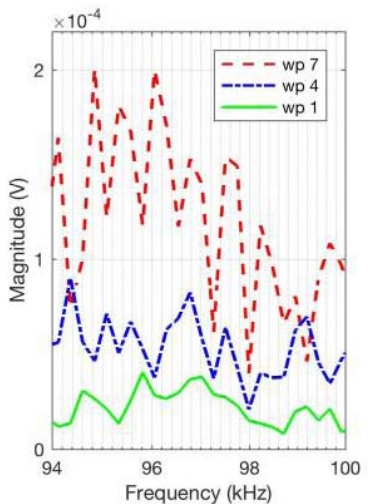

(a)

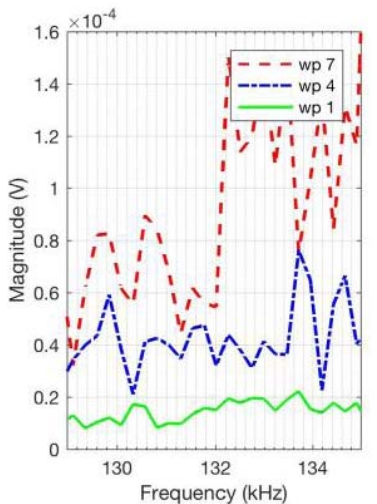

(b)
Fig. 8. Magnification for AE signal. (a) $94-100 \mathrm{kHz}$. (b) $129-135 \mathrm{kHz}$.

activities as the grinding condition becomes more severe for most ranges of frequencies. On the other hand, the opposite behavior can also be noticed for certain ranges. However, a magnification of these spectra is needed to select a proper band related to the grinding condition.

Several frequency bands were analyzed from the spectrum of each signal, and two frequency bands that best represent the surface conditions of the workpieces (normal grinding and burn) were chosen for the AE and PZT signals.

The frequency bands of $94-100 \mathrm{kHz}$ and $129-135 \mathrm{kHz}$ were chosen for AE signal, and of $50-65 \mathrm{kHz}$ and $130-140 \mathrm{kHz}$ for PZT signal. Figs. 8 and 9 show a magnification of the frequency bands for AE and PZT, respectively. It is worth mentioning that there are other frequency bands, which could also be investigated, and may be considered for further study. In these figure, wp stands for workpiece.

It can be clearly seen in the curves of Figs. 8 and 9 that the signal magnitudes are higher as grinding condition is more severe, and a minimum of overlap is observed. This behavior is of great importance to select frequency bands and possibly extract features from RMS and indices previously presented that are closely related to the workpiece surface condition.

\section{E. RMS Values From Unfiltered and Filtered Signals}

Bandpass filters were applied to the raw signals and the RMS mean values of each grinding test with their

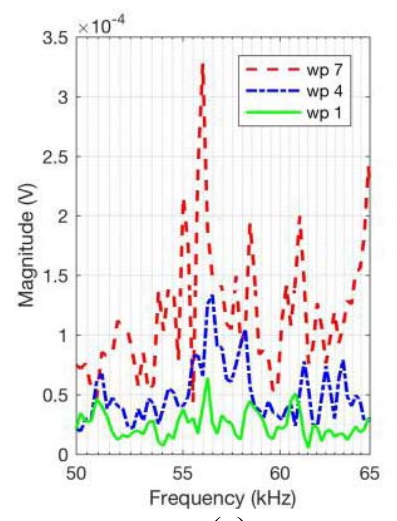

(a)

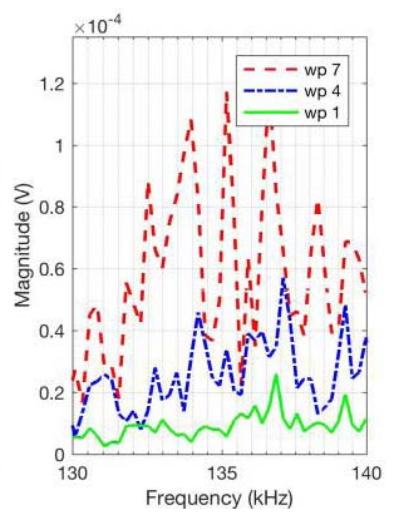

(b)
Fig. 9. Magnification for PZT signal. (a) $50-65 \mathrm{kHz}$. (b) $130-140 \mathrm{kHz}$.

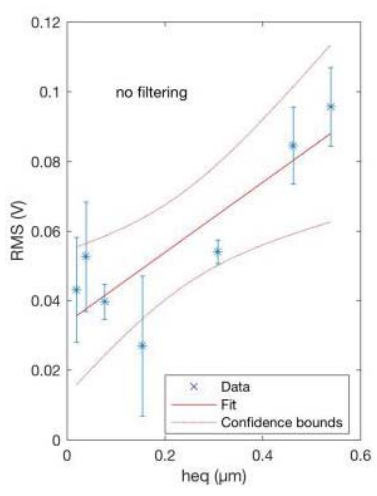

(a)

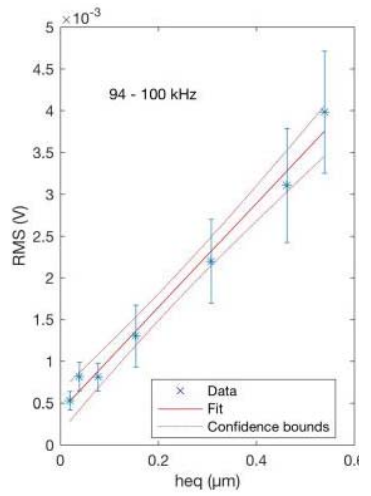

(b)
Fig. 10. RMS values for AE signals. (a) Without filtering. (b) With filtering.

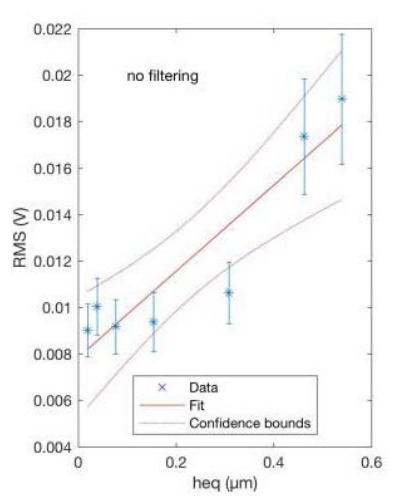

(a)

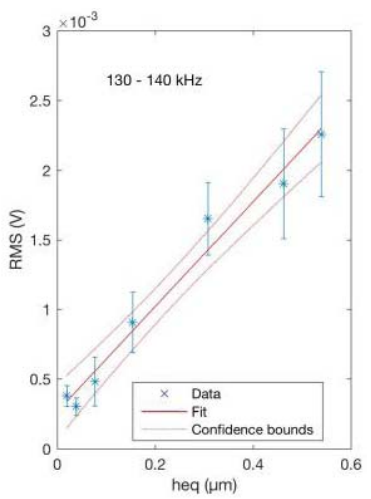

(b)
Fig. 11. RMS values for PZT signals. (a) Without filtering. (b) With filtering.

standard deviation values (grinding pass only) were obtained. Figs. 10 and 11 show the RMS values in function of the equivalent chip thickness for the raw unfiltered and filtered AE and PZT signals, respectively. The continuous line in the plots represents the regression line of the data and the outer dashed lines the confidence bounds of $95 \%$, which help better visualize the behavior of the RMS signal before and after filtering. 


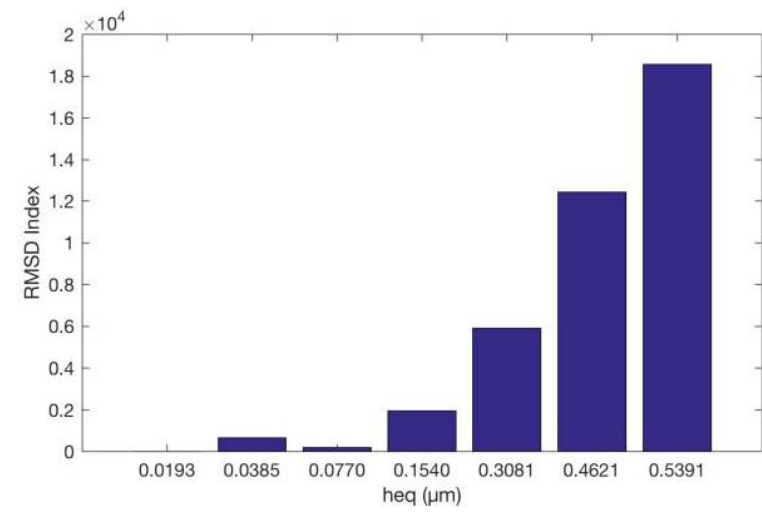

Fig. 12. RMSD for AE sensor in the band of 94-100 kHz.

In Fig. 10(a), it can be observed that AE RMS values without any digital filtering in the raw signal present a tendency of increase as the grinding condition becomes more severe. However, the data behavior does not fit so properly to the linear regression shown by the continuous red line (R-squared value of 0.736 ) and the wide confidence bound. This characteristic of the AE RMS mean values is, however, correlated with the surface roughness of the workpieces as shown in Fig. 3. The correlation of the surface roughness with the ratio of normal force and AE RMS was experimentally verified in [5] with respect to only the mean values. It can also be observed here great standard deviation values. On the other hand, a good fit of the data values to the linear regression line is clearly observed for the filtered signal, which is a desirable behavior for monitoring the process, because a threshold can be easily established to detect burn occurrence. The R-squared values for the $\mathrm{AE}$ linear regression is 0.987 for band $94-100 \mathrm{kHz}$. It can clearly be observed that a linear behavior exists between AE RMS mean values and heq when the signal is filtered. In addition, the confidence bound is narrow, which indicates very good-fitting coefficients

In the case of PZT RMS mean values shown in Fig. 11(a), the behavior of the unfiltered signal presents a better linear tendency of increase when compared with AE (R-squared of 0.857). When one examines the RMS values obtained from the raw signal filtered in the frequency band of $130-140 \mathrm{kHz}$, a very good linear fit in the RMS mean values can be observed. That is represented by the R-squared values of 0.978 and narrower confidence bounds.

It was found that the standard deviation values become higher when the grinding condition is more severe until burn occurrence, which is a characteristic used in [6] for their parameter proposed. Although the RMS with no filtering does not represent this so precisely for AE sensor, the filtered signal shows an improvement in this regard for band $94-100 \mathrm{kHz}$. In the case of PZT, the signal unfiltered presents a better standard deviation behavior when compared to AE unfiltered regarding the cutting condition. When the PZT signal is filtered in a band of $130-140 \mathrm{kHz}$, an improvement over the unfiltered can also be observed with regard to the standard deviation and grinding condition.

Based on these observations, both sensors behave quasilinearly when the signals are filtered at a frequency band

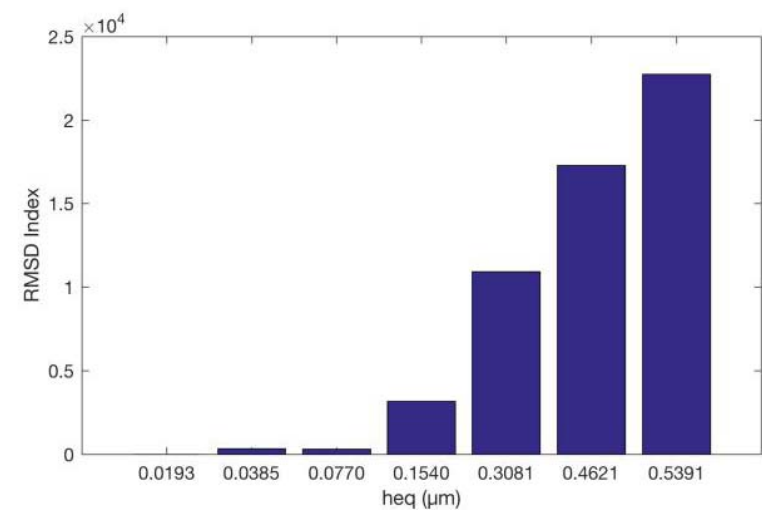

Fig. 13. RMSD for PZT sensor in a band of $130-140 \mathrm{kHz}$.

carefully selected, and in turn they are more attractive to monitor the surface condition of the workpiece. Thus, the characteristic behavior of the sensors demonstrates the importance of finding frequency bands that better represent the differences of each workpiece surface condition.

\section{F. RMSD and CCDM Indices}

As proposed, the RMSD and CCDM indices were obtained for various frequency bands. The CCDM results have presented undesirable relation with the workpiece surface conditions, that is, the indices behavior showed inconsistent oscillations with the conditions of the parts; therefore, they were not considered in this paper. In the case of RMSD, some frequency bands were found suitable for monitoring the workpiece condition, but just one was considered for this paper, that is, $94-100 \mathrm{kHz}$ for the AE sensor and $130-140 \mathrm{kHz}$ for the PZT sensor. The RMSD indices results are presented in Figs. 12 and 13 for the AE and PZT sensor, respectively.

The indices in Figs. 12 and 13 were computed by considering the power spectral density of the signals and the workpiece with the smallest depth of cut as the reference or baseline, which was the slightest grinding condition used in the grinding tests. This workpiece was verified as healthy in analyses postgrinding. It can be observed in these figures a clear tendency of increase as the grinding condition becomes more severe, and a significant difference of the index value between the intact and burned workpieces. This behavior is of great importance for establishing a threshold to monitor the workpiece surface condition and detect the occurrence of grinding burn or even workpiece with high surface roughness value. It is worth mentioning that grinding burn has just occurred in the workpieces 6 (heq $=0.4621 \mu \mathrm{m}$ ) and 7 (heq $=0.5391 \mu \mathrm{m}$ ).

\section{RESUltS AND DisCUSSION FOR METHOD VERIFICATION: SAE 1045 STEEL AND ALUMINUM OXIDE WHEEL}

In order to verify the method, as described previously in methodology section, the following results were obtained from another set of tests carried out with SAE 1045 steel workpieces and a different grinding wheel of aluminum oxide. 


\begin{tabular}{c|c|c|c|}
\hline Test 1. & Test 2. & Test 3. & Test 4. \\
\hline $5 \mu \mathrm{m}$ & $10 \mu \mathrm{m}$ & $15 \mu \mathrm{m}$ & $20 \mu \mathrm{m}$ \\
\hline Test 5. & Test 6. & Test 7. & Test 8. \\
\cline { 1 - 1 } & & & \\
\hline $25 \mu \mathrm{m}$ & $35 \mu \mathrm{m}$ & $45 \mu \mathrm{m}$ & $55 \mu \mathrm{m}$ \\
\hline
\end{tabular}

Fig. 14. Surface condition of the ground workpiece at different depths of cut.

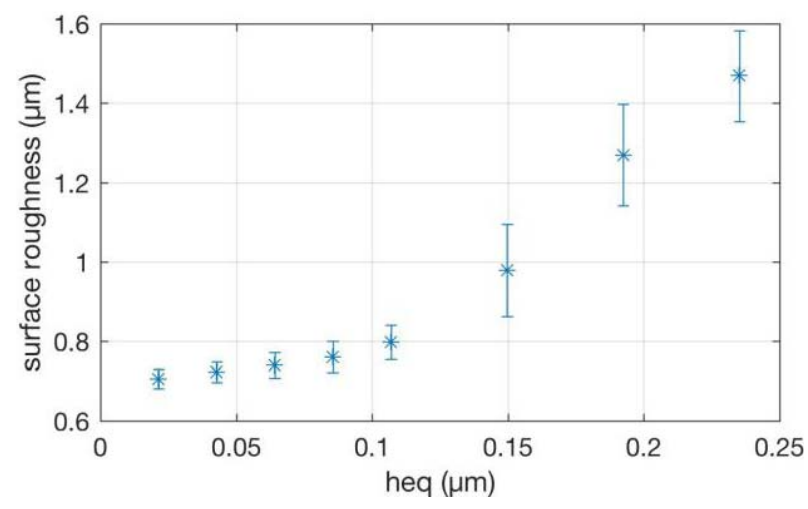

Fig. 15. Surface roughness for each workpiece.

\section{A. Visual Inspection of the Workpiece Surface}

The workpieces surfaces were also photographed and digitalized, and again aiming to assess the images and visually identify different conditions, such as normal grinding and burn. Fig. 14 shows the workpiece surfaces.

It is worth mentioning that the type of grinding wheel employed in these experimental tests generates more heat in the cutting zone and, therefore, the wheel wear takes place more rapidly compared to the first experimental tests for a given depth of cut [18]. Thus, the depth of cut of the second experimental tests should be smaller in order to get the same surface conditions of the workpieces for both experimental tests, allowing for an effective verification of the detection method of grinding burn proposed in this paper.

It is possible to observe the color alteration on the workpiece surface from Fig. 14. In the tests 1, 2 and 5, the surfaces present no change in color, which stands visually for normal grinding; in tests 3 and 4, slight burn occurrences on the upper side of the workpieces can be observed; a more intensive burn, but not severe, can be seen all over the surface in test 6 ; and finally, severe burn has occurred in tests 7 and 8 , as dark color appears along the workpiece surface.

\section{B. Surface Roughness}

Fig. 15 shows the mean values and standard deviation of the surface roughness in function of heq.

It can be observed that the roughness values are related to the grinding condition (heq), as was also observed for the other experiments presented in Section IV, and this trend can be verified in [32]. In addition, only workpieces 7 (heq $=$ $0.1924 \mu \mathrm{m}$ ) and 8 (heq $=0.2352 \mu \mathrm{m}$ ) can be considered out

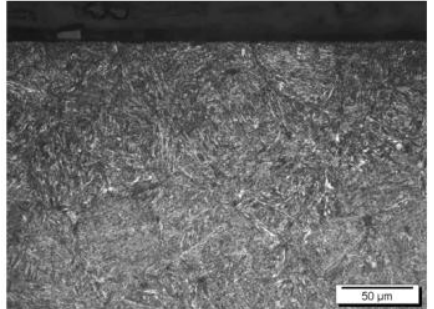

(a)

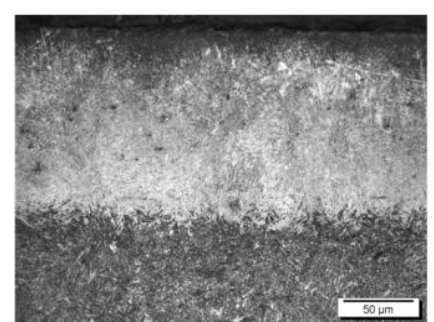

(b)
Fig. 16. Metallography for (a) good condition and (b) burn workpieces 2 and 8 , respectively.

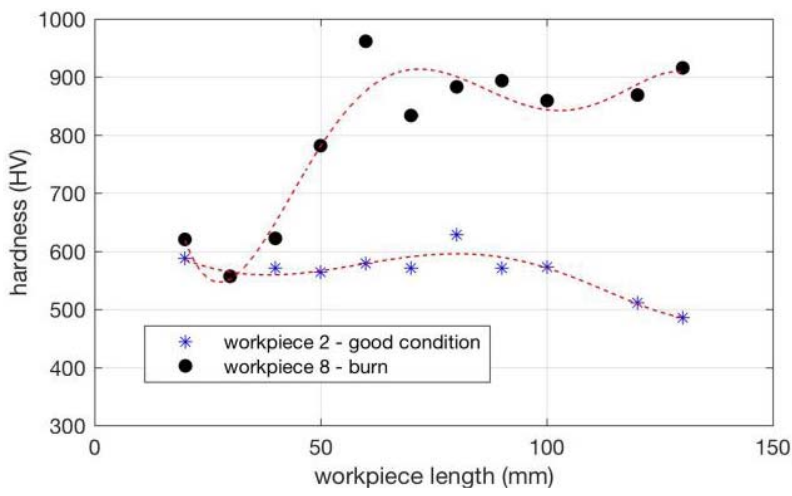

Fig. 17. Vickers hardness measurements.

of the range of average applications [31]. Furthermore, the standard deviation values for workpieces 1-5 are small when compared to larger values observed for workpieces $6-8$. This behavior is expected because the more aggressive the grinding condition, the more variation in the surface irregularities along the ground workpiece, which can also be verified in [34]. This aspect is augmented when the grinding burn occurs. The surface roughness is a key parameter to assess the workpiece surface finish and in turn comply with the project specification. However, it cannot be sufficient to detect damage, since a workpiece with damage can show acceptable values of surface roughness as verified in [34]. Therefore, other techniques are needed for this purpose.

\section{Metallography and Vickers Hardness for Verifying Tests}

Although metallographic analysis was performed in each workpiece, only two were selected in order to present the main results, that is, workpiece 2 (heq $=0.0428$ ) and workpiece 8 (heq $=0.2352$ ).

It can be observed in Fig. 16(a) that the martensitic structure remains intact, which denotes a good surface condition, that is, without any damage. On the contrary, in Fig. 16(b), the exceeding temperature on grinding zone provoked microstructural alteration that can be conferred through the formation of a thick white layer due to significant increase in temperature in the grinding zone, and thus proving again the occurrence of the burn phenomenon.

Vickers hardness tests were also performed for the verification workpieces, however, only the measurements for workpieces 2 and 8 were selected and shown in Fig. 17. The range of hardness HV values for workpiece with good condition is around the values normally applied in industry, 


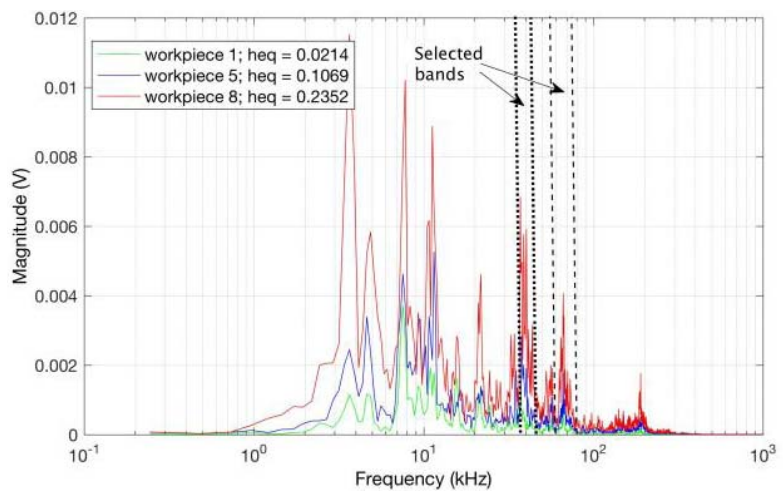

Fig. 18. Spectra of AE of new tests.

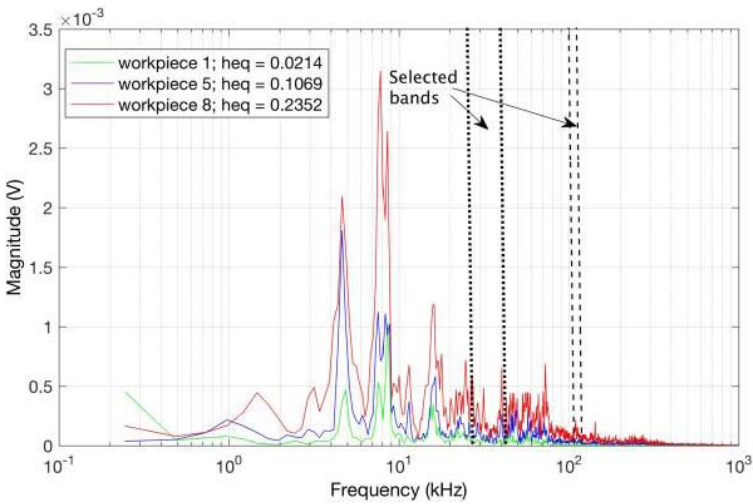

Fig. 19. Spectra of PZT signal of new tests.

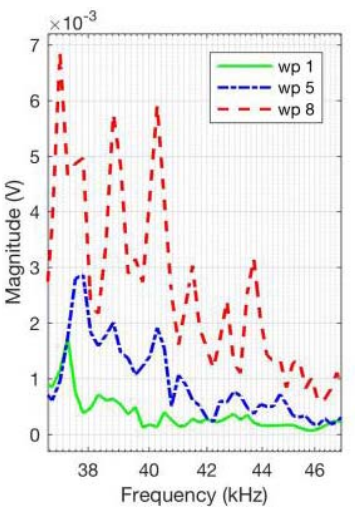

(a)

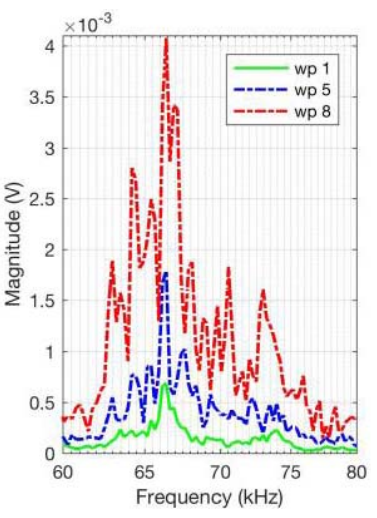

(b)
Fig. 20. Magnification for AE signal. (a) $38-46 \mathrm{kHz}$. (b) $60-80 \mathrm{kHz}$.

as described previously. On the other hand, workpiece 8 reached values of more than $900 \mathrm{HV}$, which is due to the white layer formation as verified in the metallographic analysis.

Therefore, based on the metallographic analyses and hardness measurements, the grinding burn occurrence was only verified for workpiece 7 (heq $=0.1924)$ and workpiece $8($ heq $=0.2352)$.

\section{Selection of Frequency Bands for the Verifying Tests}

Figs. 18 and 19 show the spectra of the AE and piezoelectric sensors, respectively, for three distinct grinding conditions. It can be seen that the range of the spectra is similar when compared to the previous tests carried out for a different grinding wheel, which demonstrates the quality of the PZT sensor compared to the AE sensor.

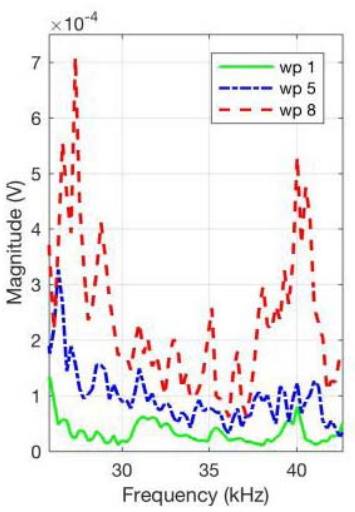

(a)

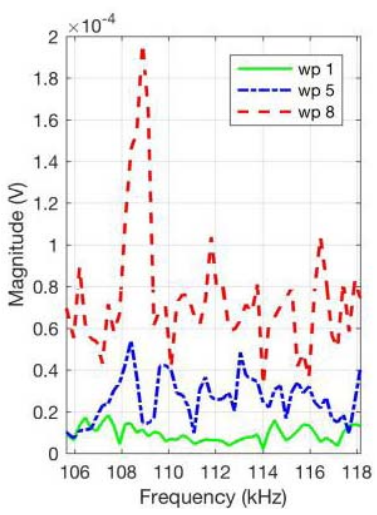

(b)
Fig. 21. Magnification for PZT signal. (a) $27-42 \mathrm{kHz}$. (b) $107-117 \mathrm{kHz}$.

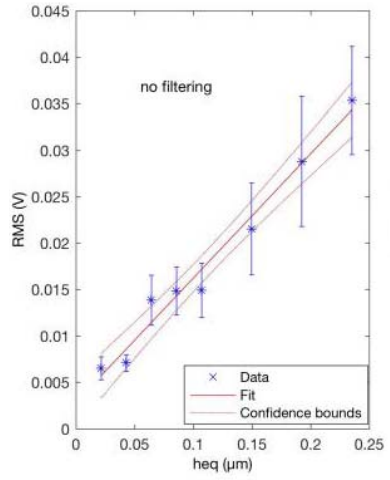

(a)

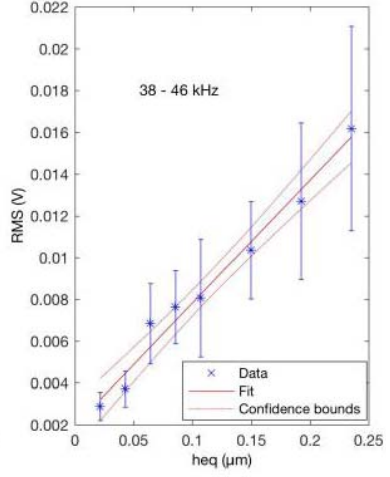

(b)
Fig. 22. RMS values for AE signals. (a) Without filtering. (b) With filtering.

The characteristic spectrum behavior for workpiece 8 , which has undergone burn, shows in general the greatest amplitudes. On the other hand, the spectrum behavior for workpieces 1 and 5 presented lower amplitudes in agreement with their grinding condition, that is, the higher the grinding condition, the higher the amplitude. However, in some regions overlaps can be noticed, but a magnification of these spectra is needed in order to select the best frequency bands related to the surface condition of the workpieces.

Thus, the spectra were thoroughly analyzed in order to find frequency bands closely related to the surface condition of the workpieces. The frequency bands of $38-46 \mathrm{kHz}$ and $60-80 \mathrm{kHz}$ were found for $\mathrm{AE}$, and of $27-42 \mathrm{kHz}$ and $107-117 \mathrm{kHz}$ for PZT. Figs. 20 and 21 show the magnification of two frequency bands for each sensor.

It can be noticed in Figs. 20 and 21 that when the frequency band is magnified, a clear distinct behavior of each spectrum is present. This observation allows for the choice of frequency bands in which the amplitudes increase as the grinding condition becomes more severe. Also, a minimum of overlap among the curves is sought.

\section{E. RMS Values From Unfiltered and Filtered Signal}

Figs. 22 and 23 show the RMS values obtained from unfiltered and filtered raw signals for both AE and PZT sensors, respectively. The filtered signals are shown only for frequency bands of $38-46 \mathrm{kHz}$ and $107-117 \mathrm{kHz}$ for $\mathrm{AE}$ and 


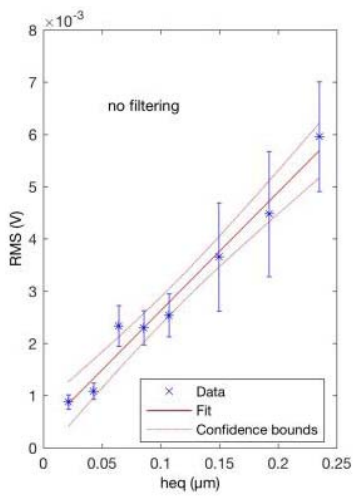

(a)

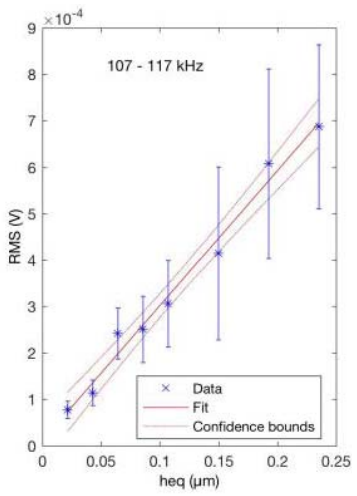

(b)
Fig. 23. RMS values for PZT signals. (a) Without filtering. (b) With filtering.

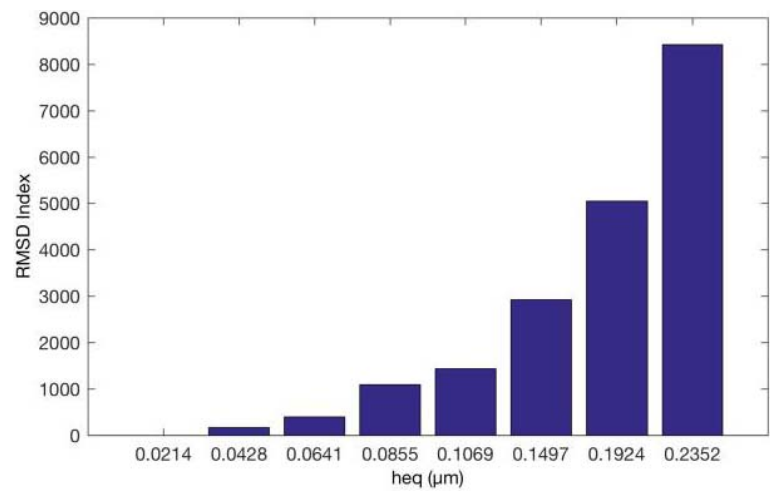

Fig. 24. RMSD for AE sensor in the band of $38-46 \mathrm{kHz}$.

PZT, respectively. The increase trend in these values shows that a relationship of the RMS and the cutting condition (heq) also exists and can be used as a tool for monitoring the process. In addition, the RMS values fit linearly well for both unfiltered and filtered signals. However, the filtered signals have presented a very good-fitting regression, whose R-squared values of 0.978 and 0.984 were found for AE and PZT, respectively. The confidence bounds of the linear regression for AE and PZT filtered and unfiltered are nearly the same, showing a good fitting in both cases. However, the standard deviations are more pronounced for filtered PZT and AE, which better reflects the behavior of the workpiece surface condition, as previously observed in Section IV. Therefore, this signal characteristic behavior is of most importance for a monitoring system, where a threshold can easily be set to detect the occurrence of grinding burn, and even to determine a surface roughness limit in order to comply with the workpiece surface specifications.

\section{F. RMSD and CCDM Indices}

The CCDM indices did not present a good relation with the surface conditions for these new tests, and again they were not considered. The RMSD indices were obtained for various bands. However, only the results for frequency band of $38-46 \mathrm{kHz}$ for AE, Fig. 24, and $107-117 \mathrm{kHz}$ for PZT, Fig. 25, are shown. It can be clearly seen in these figures the

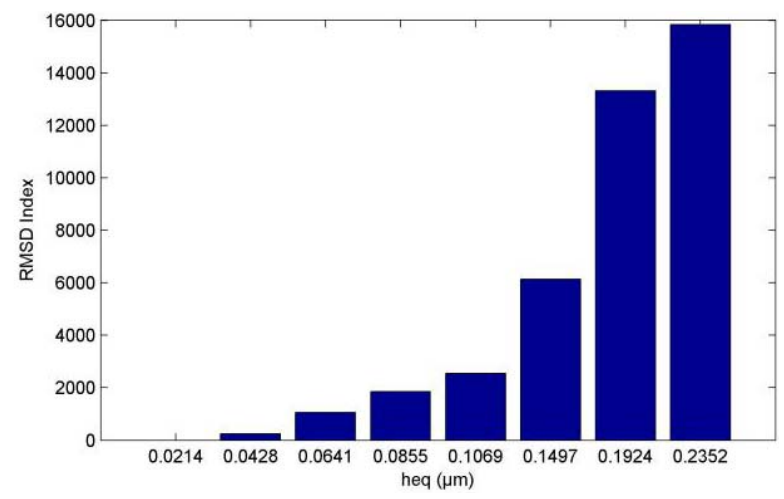

Fig. 25. RMSD for PZT sensor in the band of $107-117 \mathrm{kHz}$.

increase trend of the index value as the grinding condition becomes more severe for both sensors. Also, the index values for workpieces 7 (heq $=0.1924)$ and 8 (heq $=0.2352$ ), in which the grinding burn were verified, are much higher than those for other workpieces. Therefore, the RMSD index turned out to be a very good indicator for monitoring the damage of the workpiece with respect to the grinding burn.

\section{CONCLUSION}

In this paper, a piezoelectric diaphragm was applied for monitoring the grinding process, aiming to assess the workpiece surface in grinding with respect to normal grinding and burn occurrence. The PZT sensor was also compared to the AE sensor, which is widely used for monitoring in several fields of applications. The use of a low-cost piezoelectric diaphragm for grinding process monitoring is relatively new, and there are several other possibilities of studies and applications.

The results show a typical characteristic behavior of the surface roughness values, which were also observed in other scientific works cited herein, that is, the surface roughness values of the workpieces increase as the grinding condition becomes more severe. However, it could be verified the occurrence of burn just through the hardness measurements and metallographic analyses, where the microscopic photographs showed the formation of white layers for workpieces burned and the hardness values were over the limit. It is worth mentioning that the visual inspection showed workpieces with burn marks, but they were in fact cosmetic for most of the workpieces as revealed through the metallographic and hardness tests.

It could be clearly verified that there is a better fitting in the linear regression of the RMS mean values when the signals are filtered in the frequency bands, allowing for the implementation of a monitoring system to detect the workpiece burn. It is worth mentioning that the RMS standard deviation was more related to the surface condition when the signals were filtered, since it increases when the cutting condition is more severe. Also, the constant trend in increase of RMSD index revealed it as a potential tool for monitoring the grinding burn occurrence.

The verifying tests and results demonstrate the assurance and reliability of the proposed method, which can be extended to other materials and grinding conditions. 
Finally, it is worth mentioning that the use of the lowcost piezoelectric diaphragm in the grinding process is of great importance and contribution to scientific community and industry, since it showed good response compared to the traditional AE sensor. Therefore, it can be explored in different ways and applications in further research works.

\section{ACKNOWLEDGMENT}

The authors would like to thank NORTON of Saint Gobain Group for the donation of the grinding wheels.

\section{REFERENCES}

[1] T. W. Liao, F. Tang, J. Qu, and P. J. Blau, "Grinding wheel condition monitoring with boosted minimum distance classifiers," Mech. Syst. Signal Process., vol. 22, no. 1, pp. 217-232, Jan. 2008.

[2] D. Axinte, N. Gindy, K. Fox, and I. Unanue, "Process monitoring to assist the workpiece surface quality in machining," Int. J. Mach., vol. 44, no. 10, pp. 1091-1108, Aug. 2004.

[3] R. Babel, P. Koshy, and M. Weiss, "Acoustic emission spikes at workpiece edges in grinding: Origin and applications," Int. J. Mach. Tools Manuf., vol. 64, pp. 96-101, Apr. 2013.

[4] Z. Wang, P. Willett, P. R. DeAguiar, and J. Webster, "Neural network detection of grinding burn from acoustic emission," Int. J. Mach. Tools Manuf., vol. 41, no. 2, pp. 283-309, Jan. 2001.

[5] J. Webster, I. Marinescu, and R. Bennett, "Acoustic emission for processes control and monitoring of surface integrity during grinding," CIRP Ann. Manuf. Technol., vol. 43, no. 1, pp. 299-304, 1994.

[6] P. Aguiar, E. Bianchi, and J. Oliveira, "A method for burning detection in grinding process using acoustic emission and effective electrical power signal," CIRP J. Manuf. Syst., vol. 31, no. 3, pp. 253-257, 2002.

[7] A. Hassui, A. E. Diniz, J. F. G. Oliveira, J. Felipe, and J. J. F. Gomes, "Experimental evaluation on grinding wheel wear through vibration and acoustic emission," Wear, vol. 217, no. 1, pp. 7-14, Apr. 1998.

[8] R. Teti, K. Jemielniak, G. O'Donnell, and D. Dornfeld, "Advanced monitoring of machining operations," CIRP Ann. Manuf. Technol., vol. 59, no. 2, pp. 717-739, Jan. 2010

[9] J.-H. Zhou, C. K. Pang, Z.-W. Zhong, and F. L. Lewis, "Tool wear monitoring using acoustic emissions by dominant-feature identification," IEEE Trans. Instrum. Meas., vol. 60, no. 2, pp. 547-559, Feb. 2011.

[10] C. H. R. Martins, P. R. Aguiar, A. Frech, and E. C. Bianchi, "Tool condition monitoring of single-point dresser using acoustic emission and neural networks models," IEEE Trans. Instrum. Meas., vol. 63, no. 3 , pp. 667-679, Mar. 2014.

[11] B. Castro et al., "Partial discharge monitoring in power transformers using low-cost piezoelectric sensors," Sensors, vol. 16, no. 8, p. 1266 , 2016.

[12] H. A. Tinoco and D. J. Marulanda, "Damage identification in active plates with indices based on Gaussian confidence ellipses obtained of the electromechanical admittance," J. Nondestruct. Eval., vol. 34, no. 3, p. 28,2015 .

[13] E. S. De Freitas and F. G. Baptista, "Experimental analysis of the feasibility of low-cost piezoelectric diaphragms in impedance-based SHM applications," Sens. Actuators. A Phys., vol. 238, pp. 220-228, May 2016.

[14] R. Liang and Q. M. Wang, "High sensitivity piezoelectric sensors using flexible PZT thick-film for shock tube pressure testing," Sens. Actuators A Phys., vol. 235, pp. 317-327, Sep. 2015.

[15] P. de Aguiar, P. Willett, and J. Webster, "Acoustic emission applied to detect workpiece burn during grinding," in Proc. ASTM Int. Acoust. Emission Standards Technol. Update, 1999, pp. 107-118.

[16] S. Santa-Aho, Barkhausen Noise Method for Hardened Steel Surface Characterization-the Effect of Heat Treatments, Thermal Damages and Stresses. Tampere, Finland: Tampere Univ. Technol., 2012.

[17] S. K. Singh, K. Srinivasan, and D. Chakraborty, "Acoustic characterization and prediction of surface roughness," J. Mater. Process. Technol., vol. 152 , no. 2 , pp. 127-130, Oct. 2004.

[18] S. Malkin and C. Guo, Grinding Technology: Theory and Applications of Machining With Abrasives, 2nd ed. New York, NY, USA: Industrial Press, 2008.

[19] M. E. Nakai, P. R. Aguiar, H. Guillardi, E. C. Bianchi, D. H. Spatti, and D. M. D'Addona, "Evaluation of neural models applied to the estimation of tool wear in the grinding of advanced ceramics," Expert Syst. Appl., vol. 42 , no. 20 , pp. 7026-7035, 2015.
[20] M. Subramanian, M. Sakthivel, K. Sooryaprakash, and R. Sudhakaran, "Optimization of end mill tool geometry parameters for A17075-T6 machining operations based on vibration amplitude by response surface methodology," Measurement, vol. 46, no. 10, pp. 4005-4022, 2013.

[21] R. F. G. Neto, M. Marchi, C. Martins, P. R. Aguiar, and E. Bianchi, "Monitoring of grinding burn by $\mathrm{AE}$ and vibration signals," in Proc. 6th Int. Conf. Agents Artif. Intell., 2014, pp. 272-279.

[22] H. Yoo, Z. Liu, N. N. Quang, S. Kim, and F. Bien, "Implementation of nondestructive crack detection system for automotive press panel," IEEE Sensors J., vol. 16, no. 2, pp. 383-389, Sep. 2016.

[23] A. Ledeczi, T. Hay, P. Volgyesi, D.-R. Hay, A. Nadas, and S. Jayaraman, "Wireless acoustic emission sensor network for structural monitoring," IEEE Sensors J., vol. 9, no. 11, pp. 1370-1377, Nov. 2009.

[24] D. F. G. Moia, I. H. Thomazella, P. R. Aguiar, E. C. Bianchi, C. H. R. Martins, and M. Marchi, "Tool condition monitoring of aluminum oxide grinding wheel in dressing operation using acoustic emission and neural networks," J. Brazilian Soc. Mech. Sci. Eng., vol. 37, no. 2, pp. 627-640, 2015 .

[25] M. Marchi, F. G. Baptista, P. R. de Aguiar, and E. C. Bianchi, "Grinding process monitoring based on electromechanical impedance measurements," Meas. Sci. Technol., vol. 26, no. 4, p. 45601, 2015.

[26] P. R. Aguiar, E. C. Bianchi, and J. F. G. Oliveira, "A method for burning detection in grinding process using acoustic emission and effective electric power signals," Manuf. Syst., vol. 31, no. 3, pp. 253-257, 2002.

[27] H. I. C. Miranda, P. R. Aguiar, C. D. G. Euzebio, and E. C. Bianchi, "Fuzzy logic to predict thermal damages of ground parts," in Proc. 10th IASTED Int. Conf. Artif. Intell. Appl. (AIA), 2010, pp. 434-441.

[28] C. E. D. Cruz, P. R. Aguiar, R. Machado, E. C. Bianchi, J. G. Contrucci, and F. C. Neto, "Monitoring in precision metal drilling process using multi-sensors and neural network," Int. J. Adv. Manuf. Technol., vol. 66, nos. 1-4, pp. 151-158, Jun. 2012.

[29] V. A. D. de Almeida, F. G. Baptista, and P. R. de Aguiar, "Piezoelectric transducers assessed by the pencil lead break for impedancebased structural health monitoring," IEEE Sensors J., vol. 15, no. 2, pp. 693-702, Feb. 2015.

[30] J. Webster, W. P. Dong, and R. Lindsay, "Raw acoustic emission signal analysis of grinding process," CIRP Ann. Manuf. Technol., vol. 45, no. 1, pp. 335-340, 1996

[31] K. Schmid, Manufacturing Engineering and Technology, 7th ed. Jurong, Singapore: Pearson Education, 2001.

[32] F. Klocke, E. Brinksmeier, and K. Weinert, "Capability profile of hard cutting and grinding processes," CIRP Ann. Manuf. Technol., vol. 54, no. 2, pp. 22-45, 2005.

[33] R. D. Nathan, L. Vijayaraghavan, and R. Krishnamurthy, "In-process monitoring of grinding burn in the cylindrical grinding of steel," J. Mater Process. Technol., vol. 91, no. 1, pp. 37-42, 1999.

[34] W. R. do Nascimento, A. A. Yamamoto, H. J. de Mello, R. C. Canarim, P. R. de Aguiar, and E. C. Bianchi, "A study on the viability of minimum quantity lubrication with water in grinding of ceramics using a hybridbonded diamond wheel," Inst. Mech. Eng. B, J. Eng. Manuf., vol. 230, no. 9 , pp. 1630-1638, Sep. 2016.

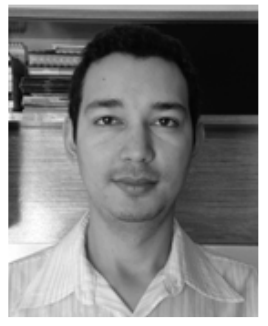

Danilo M. S. Ribeiro was born in Itaberaba-BA, Brazil, in 1986. He received the graduation degree in computer science from Faculdade de Tecnologia de Ciência de Feira de Santana-BA, Feira de Santana, Brazil, in 2008. He is currently pursuing the master's degree in mechanical engineering from the Faculdade de Engenharia, Universidade Estadual Paulista, Campus de Bauru-SP, São Paulo, Brazil, focusing on the evaluation of piezoelectric transducer applied to monitoring the workpiece surface conditions in grinding.

He is currently a Teacher of IT at Instituto Metodista de Educação-IMED (Lins-SP, Brazil) and Developer at Candido Technology (Lins-SP, Brazil). 


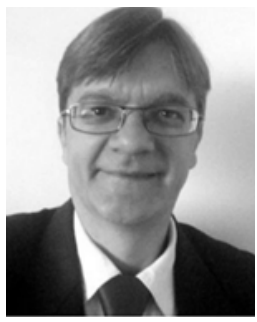

Paulo R. Aguiar received the Ph.D. degree from the University of São Paulo, São Paulo, Brazil.

He was a Post-Doctoral Researcher with the University of Connecticut, Storrs, CT, USA. He is currently a Full Professor and the Coordinator of the Electrical Engineering Graduate Program, Sao Paulo State University, São Paulo-UNESP. He has authored more than 400 papers in journals and conferences. He conducted several projects with support of State and Federal Agencies. His current research interests include digital signal processing applied to monitoring of manufacturing processes, computational intelligence, and instrumentation and measurements.

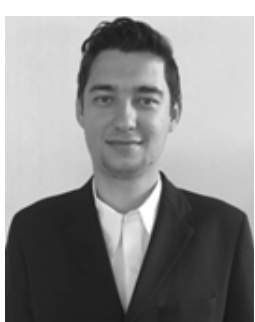

Luiz F. G. Fabiano was born in Bauru, Brazil, in 1990. He received the degree in control engineering and automation from Universidade Paulista, Bauru, Brazil, in 2012 and the master's degree in mechanical engineering from the Faculdade de Engenharia, Universidade Estadual Paulista, São Paulo, Brazil-UNESP, Campus de Bauru-SP, in 2017.

He is currently a Teacher of Professional Practices with the Serviço Nacional de Aprendizagem Industrial, Bauru, Brazil.

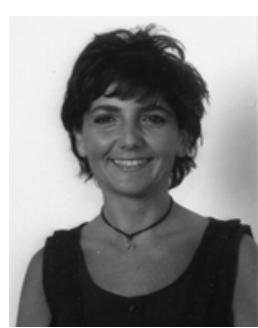

Doriana M. D'Addona received the M.Sc. degree in electronics engineering and the Ph.D. degree in intelligent technology and systems for production automation from the University of Naples Federico II, Naples, Italy, in 1999 and 2003, respectively.

During 2004-2006, she received a Post-Doctoral Fellow contract, and was with Intelligent Computation for Manufacturing Technology and Systems. She is currently an Assistant Professor with the Department of Chemical, Materials and Industrial Production Engineering, University of Naples Federico II. Her current research interests include manufacturing processes and automation, and intelligent computation for manufacturing technology and systems.

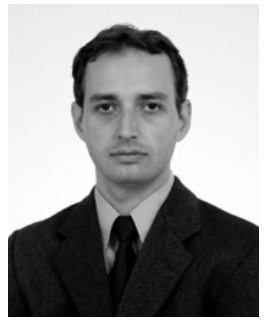

Fabricio Guimarães Baptista (S'08-M'11) received the B.S. and Ph.D. degrees in electrical engineering from the Universidade Estadual Paulista (UNESP), Bauru, Brazil, in 2006 and 2010, respectively.

He was a Visiting Scholar with the Center for Intelligent Material Systems and Structures, Virginia Polytechnic Institute and State University, Blacksburg, VA, USA, from 2010 to 2011, where he was involved in research on structural health monitoring and piezoelectric transducers. $\mathrm{He}$ is currently an Assistant Professor with the Department of Electrical Engineering, UNESP, where he coordinates the Laboratory of Transducers and Data Acquisition, focusing in the field of piezoelectricity, structural health monitoring, signal processing, data acquisition, and electronic instrumentation.

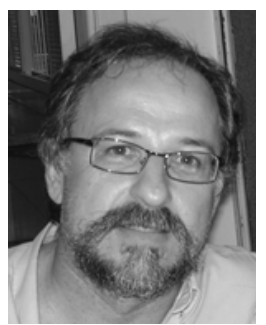

Eduardo C. Bianchi received the Ph.D. degree from the Department of Mechanical Engineering, University of São Paulo, São Paulo, Brazil.

$\mathrm{He}$ is currently a Full Professor with the Department of Mechanical Engineering, São Paulo State University. His current research interests include grinding and manufacturing processes, precision engineering, and environmentally friendly cutting fluids. 